\title{
Using Mixed Methods of Drying Dehydrated Feed for Farm Livestock in Preparation for Long-Term Storage
}

\author{
Sergei V. Shchitov, Pavel V. Tikhonchuk, Roini L. Sharvadze, Tamara A. Krasnoshchekova, \\ Julia R. Samarina, Evgeniy E. Kuznetsov, Natalia A. Kapustina and Zoya F. Krivuca \\ Far Eastern State Agrarian University, Street Polytechnic 86, Building \# 4, \\ 675005, 675009 Blagoveschensk, Russia
}

\begin{abstract}
This study describes the construction and presents the results of trials of a drying unit with infrared radiation and forced ventilation which enables preparation of dehydrated feed for long-term storage while preserving nutritional properties. The currently used methods of preparing feed for long-term storage have one significant drawback when stored for a long time, the nutritional value of feed is reduced by about $50 \%$. It is known that conservative drying of feed can prevent this process. This study contains the results of trials of an infrared drying unit with forced ventilation which is used for the preparation of feed for long-term storage under the condition of maintaining basic nutritional properties. This is especially important for small farms as the proposed drying unit is able to reduce energy costs for preparing feed for storage significantly and consequently, to reduce the product unit cost. It has been experimentally established that the application of an infrared drying unit with forced ventilation as part of the technological process of preparing feed for farm livestock enables long-term storage of feed while maintaining basic nutritional properties.
\end{abstract}

Key words: Feed ration, nutritional properties, infrared radiation, ventilation, drying unit, energy costs

\section{INTRODUCTION}

When feeding farm cattle, the main requirement for the feed ration is stable and high productivity along with the reduction in the feed unit cost. Therefore, farmers face the problem of compiling an optimal feed ration of such a biological value which would not only meet this requirement but also fully satisfy the nutritional needs of livestock in the absence of pasture and green summer forages. A possible solution to this problem is the uninterrupted supply of feed material. It can be achieved by harvesting and appropriate processing of feed for the whole cattle housing season. One of the methods of preparation of feed for long-term storage is drying. A necessary zootechnical prerequisite (Samarina et al., 2012) here is that the moisture content of the feed placed in long-term storage should be within the range of $18-20 \%$. Drying methods are distinguished by means of supplying heat. Among most frequently used methods there are convective drying, conductive (contact) drying, thermal radiation drying (by infrared rays) drying by currents of high and ultrahigh frequency and sublimation drying. All of them have advantages and disadvantages. The following drying methods are among most wide-spread and most often used currently: convective drying, sublimation drying and thermal radiation (infrared) drying (Eckert and Diaguila 1954).
The most promising of all the above methods, especially for small farms of the agrarian sector, engaged in agricultural production under the natural and climatic conditions of the Amur Region of Russia which is characterized by a high initial moisture content of the collected agricultural products is infrared drying.

By Ermolinskiy points out, the drying process is characterized by three successive stages marking the progress of the feed material through the drying unit: loading, drying in the research chamber, unloading of the dried product. With the increase in the heating temperature of the product, the specific energy consumption also increases and the quality of the product obtained drops significantly.

Several researchers established that the technology of infrared drying of wet products allows for an almost $100 \%$ utilization of the supplied energy (Vanzetti, 1972; Cuccurullo et al., 2012; Nair et al., 2015; Nair and Karuppasamy, 2015). Unlike all other types of drying, the energy emitted by infrared rays is directly applied to the moisture contained in the feed product which results in the direct heating of the water molecules. Therefore, if the heat is supplied in such a way, there's no need to raise the temperature of the drying product significantly. It has also been established that the process of evaporation of moisture inside the drying unit at a temperature of $40-60^{\circ}$ is more intense and destroys the bacterial flora on

Corresponding Author: Evgeniy E. Kuznetsov, Far Eastern State Agrarian University, Street Polytechnic 86, Building \# 4, 675005, 675009 Blagoveschensk, Russia 
the surface of the product, making it practically germfree. Infrared drying has two advantages (Borkhert and Yubic, 1953; Lebedev, 1955; Ginzburg, 1966) such temperatures allow for maximum preservation of the inner structure of the feed product and the vitamins inside, prevent the caramelization of sugars and a decline in the biological activity. Relatively low temperatures prevent heating of the construction and internal devices of the dryer which minimizes the energy losses.

Other methods require heating of the feed product up to $100-150^{\circ} \mathrm{C}$, otherwise the drying process will take rather a long time up to $20-30 \mathrm{~h}$.

Thus, the goal of the conducted research is finding new optimal solutions for increasing the efficiency of preparing feed for long-term storage which is an important component of increasing the productivity of farm livestock and ensuring the stability of the feed ration given out during the year while reducing energy costs per product unit.

In the course of previous studies (Samarina et al., 2007; Dongbang et al., 2010), it has been established that the optimal method for achieving this goal is the implementation of a mixed drying method involving infrared radiation and forced ventilation.

\section{MATERIALS AND METHODS}

An optimal piece of equipment providing for the preservation of nutritional properties of feed and slashing of energy costs for its preparation is the drying unit with infrared displayed on Fig. 1 and 2. It is recommended for use at small farms. The drying unit (Fig. 1) consists of
4 infrared heating elements (2) a movable screen plate (3) an air blower (1), a box frame (4) and an air transfer $\operatorname{duct}(5)$.

The prominent feature of the proposed drying unit is the combination of two methods of heat supply thermoradiation and convection. The unit operates in the following way: immediately after exiting the cubing and pelleting machine, the pelletized feed product is supplied to the movable screen plate. Depending on the initial moisture content of the pellets the necessary number of the heaters is turned on (from 2-4). The infrared rays heat the product for a few seconds. Simultaneously with heating, the surface of the feed is being cooled by the air flow generated by the blower. The moisture begins to migrate from the core of the feed to its surface which significantly increases the drying speed (Samarina et al., 2012; Samarina and Shchitov, 2014).

The testing of the drying unit was carried out in accordance with the recommended general and particular methods using specialized programs for mathematical calculation, experimental simulation and regression analysis methods.

For measuring of the above parameters, the laboratory test and measuring system was used. The following parameters were measured: the initial and final moisture content of the feed, friability of pelletized and cubed feed, drying unit capacity, air flow rate and directional intensity of air flux, power expended on evaporation of $1 \mathrm{~kg}$ of moisture from the surface of the product. The data obtained during the experiment was processed via. known methods of mathematical statistics on the computer.

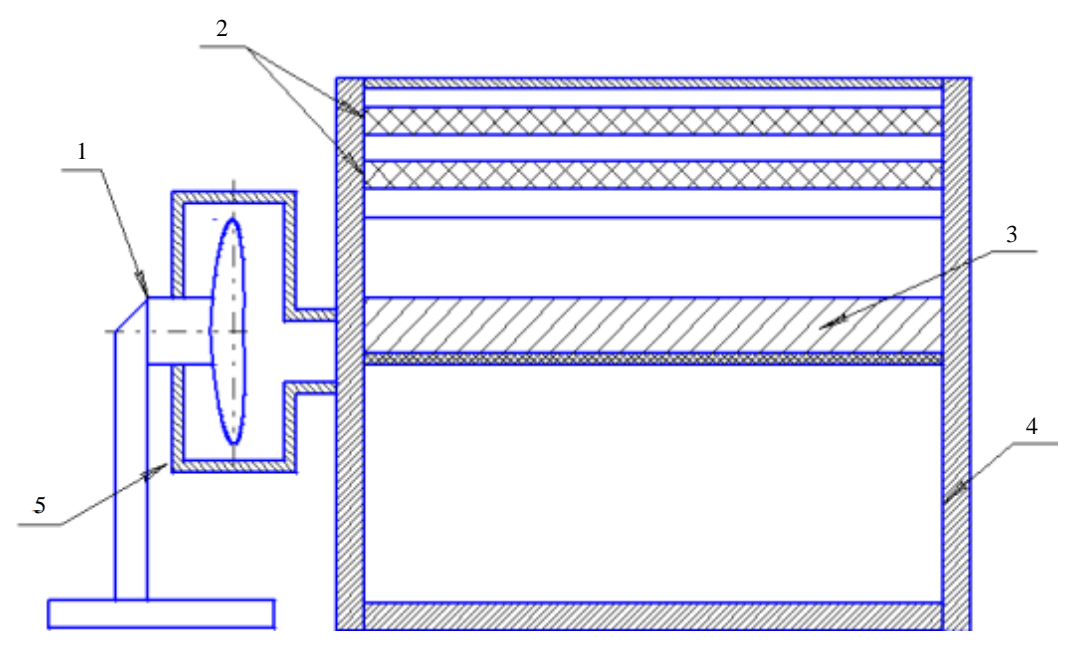

Fig. 1: Drying unit: 1) Air blower; 2) Infrared heating elements; 3) Movable screen plate; 4) Box frame and 5) Air transfer duct 


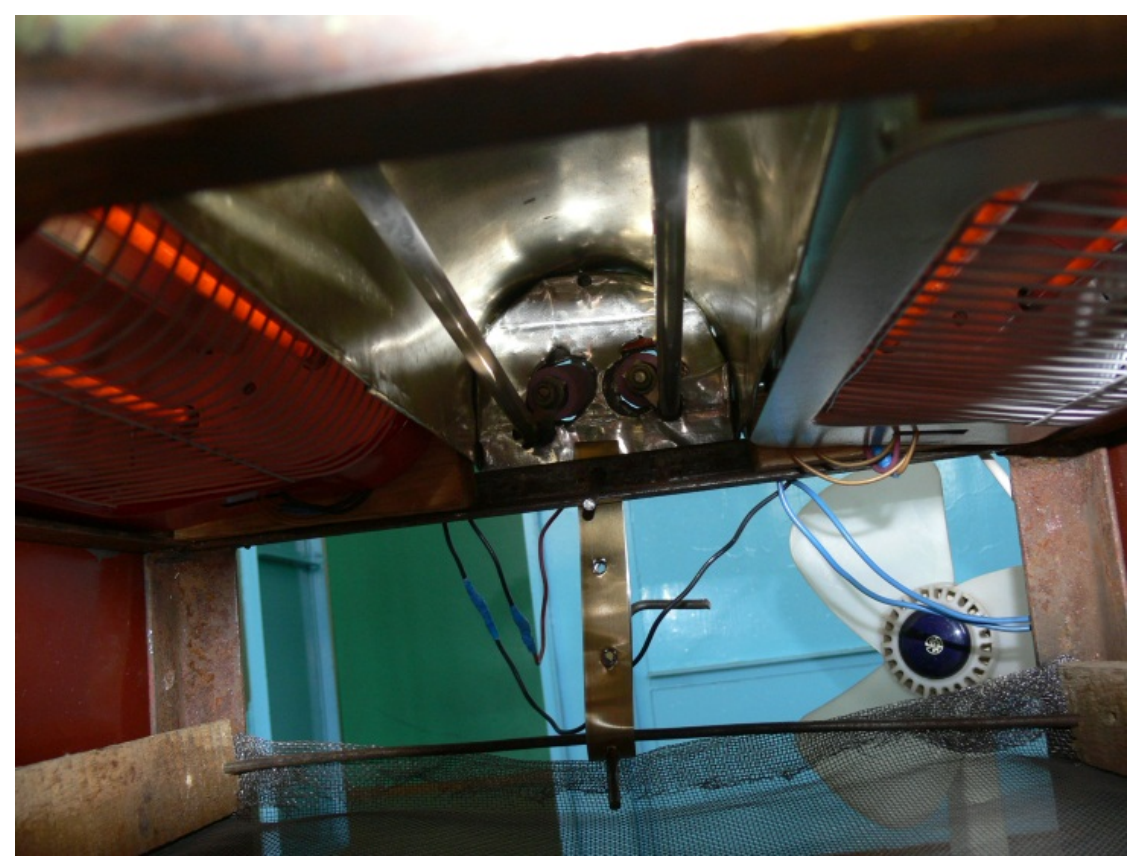

Fig. 2: General view of the drying unit

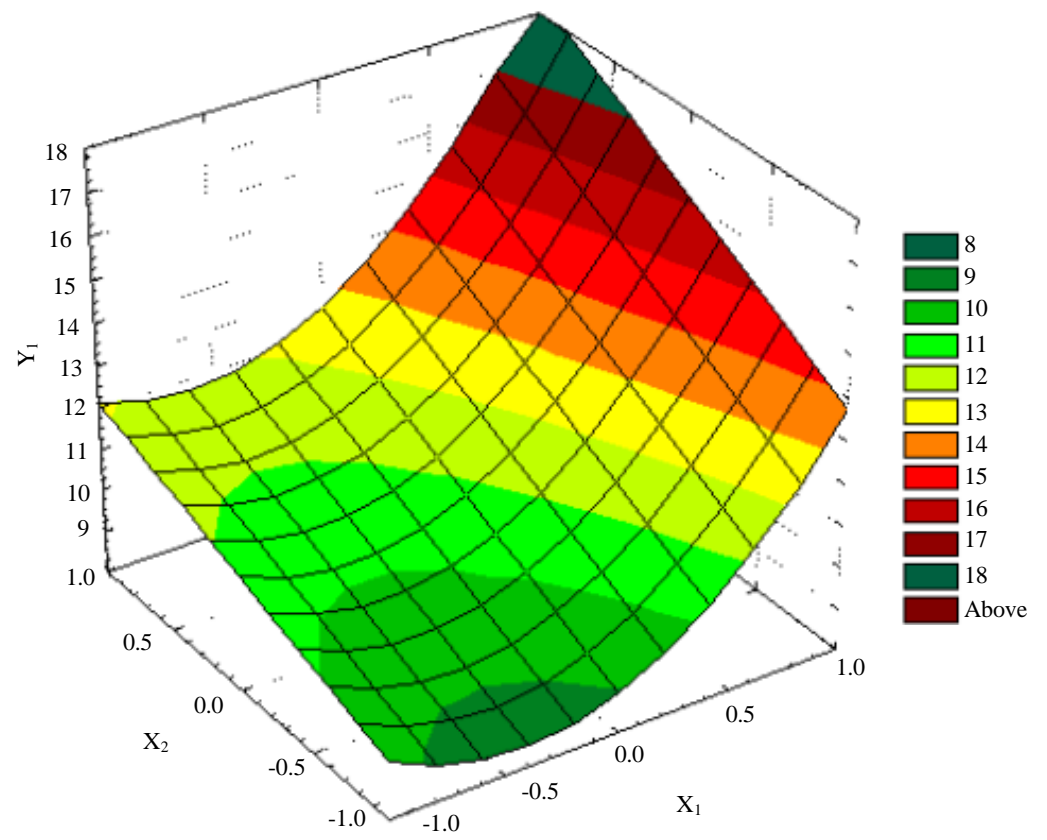

Fig. 3: The response surface $Y_{1}=f\left(X_{1}, X_{2}\right)$ at $X_{3}=0($ at $V=20 \mathrm{~m} / \mathrm{min})$ and $X_{4}=0.33$ (at $\left.W_{1}=21.98 \%\right)$

\section{RESULTS AND DISCUSSION}

Theoretical studies and experimental trials of the drying unit with infrared radiation and forced ventilation conducted at the Far Eastern State Agrarian University (Amur Region, Blagoveshchensk, the Russian Federation) and at production facilities of agricultural enterprises of the Blagoveshchensk District of the Amur Region verified the validity of the chosen method of preparing feed for long-term storage and justified the necessity for its application in feeding of farm livestock.

Experimental studies (Fig. 3) helped to establish that with an increase in the heating temperature, a decrease in the speed of blowing the surface of the feed product and 


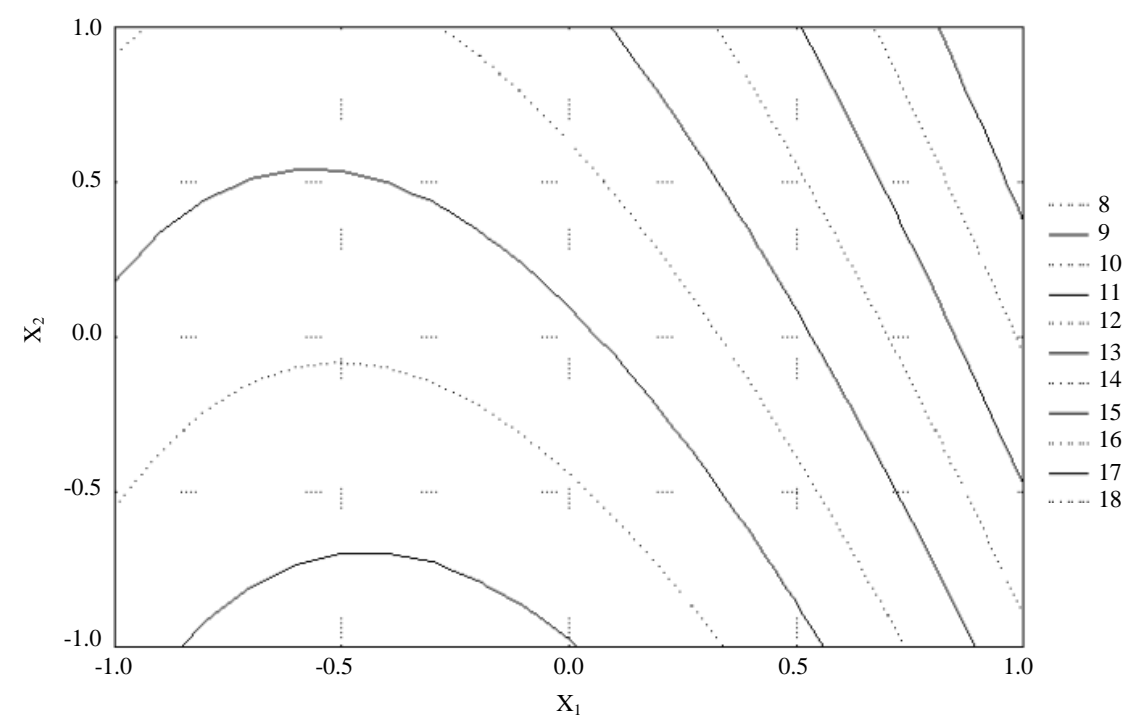

Fig. 4: Cross-section of the response surface $Y_{1}$ with the stabilization of factors $X_{3}=0$ (at $V=20 \mathrm{~m} / \mathrm{min}$ ) and $X_{4}=0.33$ (at $\left.\mathrm{W}_{1}=21.98 \%\right)$

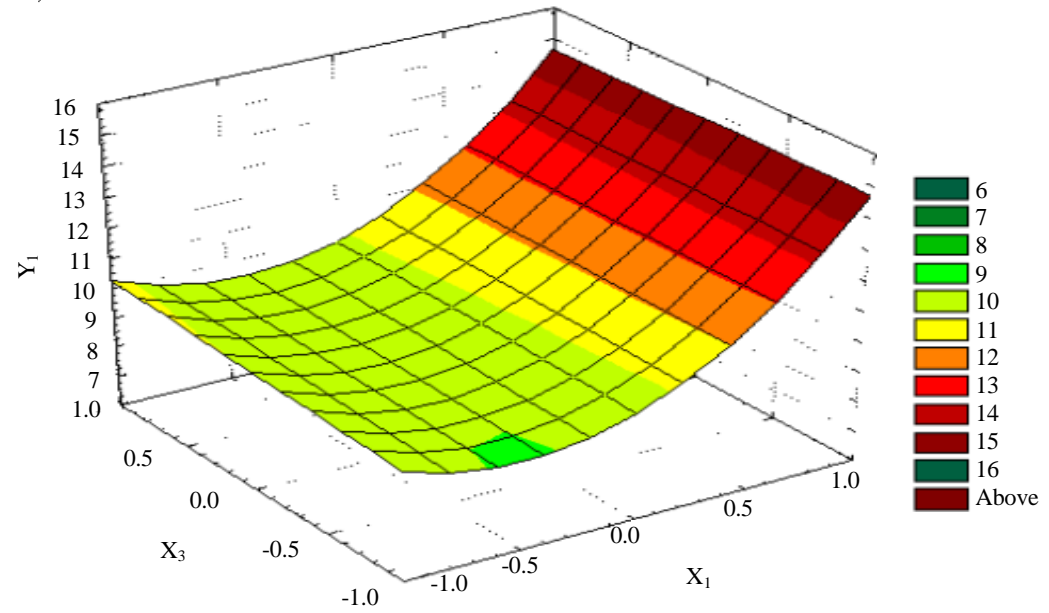

Fig. 5: The response surface $\mathrm{Y}_{1}=\mathrm{f}\left(\mathrm{X}_{1}, \mathrm{X}_{3}\right)$ at $\mathrm{X}_{2}=-0.60$ (at $\mathrm{X}=22 \mathrm{~min}$ ) and $\mathrm{X}_{4}=0.33\left(\right.$ at $\mathrm{W}_{1}=21.98 \%$ )

a decrease in the duration of the drying process, the specific power of the unit decreases. With an increase in the heating temperature and a decrease in the initial moisture content of the granulated feed while reducing the duration of the drying process, a decrease in the final moisture content of the granulated feed is observed (Samarina et al., 2007; Samarina and Shchitov, 2014).

To analyze the impact of interacting factors on the process of drying of feed, we constructed graphic response surfaces and cross-sections of the response surface (Fig. 3-7) using the special-purpose software "Mathcad 2000 Professional".

In this case, the original regression equations were reduced to polynomial equations with two factors and the remaining interacting values were left at constant levels. The following parameters were set as variation factors: $\mathrm{X}_{1}$ heating temperature of the feed material surface $\left(\mathrm{t}^{\circ}\right),{ }^{\circ} \mathrm{C}, \mathrm{X}_{2}$ duration of drying $(\tau), \mathrm{min}, \mathrm{X}_{3}$-air supply intensity $(\mathrm{V}), \mathrm{m} / \mathrm{min} ; \mathrm{X}_{4}$-initial moisture content of the feed material $\left(\mathrm{W}_{1}\right), \%$. The following parameters were set as final values: $Y_{1}$-specific power of the unit (Nуд), W/kg and $\mathrm{Y}_{2}$-final moisture content of the feed material $(\mathrm{W}), \%$.

Based on the analysis of the response surface graph (Fig. 5) and the cross-section of the response surface (Fig. 6), it can be concluded that with the stabilization of factors $\mathrm{X}_{3}=0$ (at $\mathrm{V}=20 \mathrm{~m} / \mathrm{min}$ ) and $\mathrm{X}_{4}=$ $0.33\left(\right.$ at $\left.\mathrm{W}_{1}=21.98 \%\right)$ the specific power $\left(\mathrm{Y}_{1}\right)$ increases in the limit as $\mathrm{X}_{2}(\tau)$ and $\mathrm{X}_{1}(\mathrm{t})$ near the upper level. 


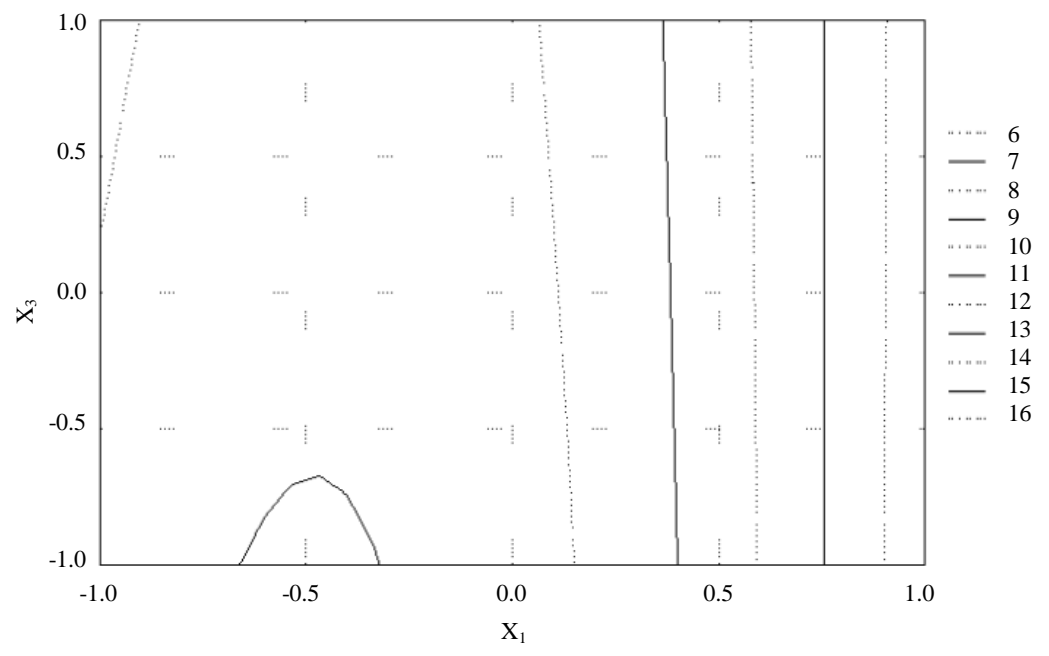

Fig. 6: Cross-section of the response surface $Y_{1}$ with the stabilization of factors $X_{2}=-0.60$ (at $X=22 \mathrm{~min}$ ) and $\mathrm{X}_{4}=0.33$ (at $\left.\mathrm{W}_{1}=21.98 \%\right) ; \mathrm{Y}_{1}=\mathrm{f}\left(\mathrm{X}_{1}, \mathrm{X}_{2}, \mathrm{X}_{3}=-0.60, \mathrm{X}_{3}, \mathrm{X}_{4},=0.33\right.$ )

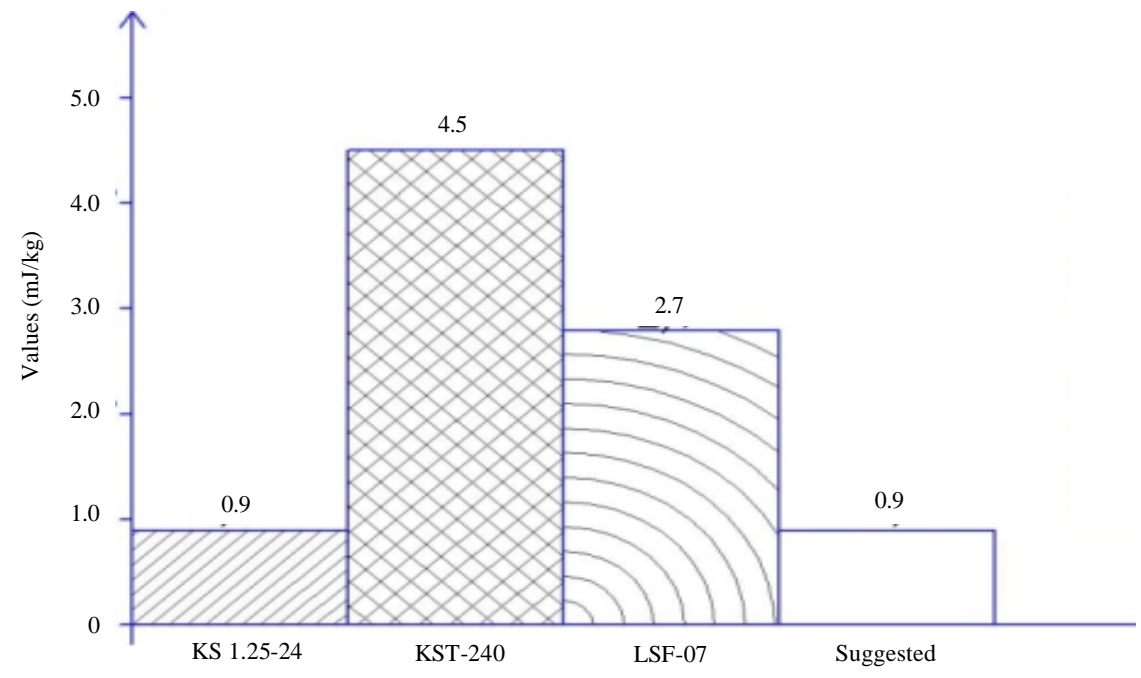

Fig. 7: Labor outlays $(\mathrm{mJ} / \mathrm{kg})$

Provided the stabilization of factors $\mathrm{X}_{2}=-0.60$ (at $\tau=22 \mathrm{MnH}$ ) and $\mathrm{X}_{4}=0.33$ (at $\mathrm{W}_{1}=21.98 \%$ ), the specific power $\left(\mathrm{Y}_{1}\right)$ increases in the limit as $\mathrm{X}_{3}(\mathrm{~V})$ and $\mathrm{X}_{1}$ (t) tend to the upper level.

The results of the conducted studies allowed to establish that the following variation factors influence the determination of the final parameters: specific power: $\mathrm{X}_{1}$-heating temperature of the feed material surface $(\mathrm{t}),{ }^{\circ} \mathrm{C}$, $\mathrm{X}_{2}$-duration of drying $(\tau)$, min, $\mathrm{X}_{3}$-air supply intensity $(\mathrm{V})$, $\mathrm{m} / \mathrm{min}$.

Final moisture content of the feed material: $\mathrm{X}_{1}$-heating temperature of the feed material surface $(\mathrm{t}),{ }^{\circ} \mathrm{C}$, $\mathrm{X}_{2}$-duration of drying $(\tau), \mathrm{min}, \mathrm{X}_{3}$-air supply intensity $(\mathrm{V})$, $\mathrm{m} / \mathrm{min}, \mathrm{X}_{4}$-initial moisture content of the feed material $\left(\mathrm{W}_{1}\right), \%$.
As a result of experimental studies, the following optimum values of the parameters were determined: $\mathrm{X}_{1}$-heating temperature of the feed material surface $\mathrm{t}=43^{\circ} \mathrm{C}, \mathrm{X}_{2}$-duration of drying $\tau=23 \mathrm{~min}, \mathrm{X}_{3}$-air supply intensity $\mathrm{V}=20 \mathrm{~m} / \mathrm{min}, \mathrm{X}_{4}$-initial moisture content of the feed material $\mathrm{W}_{1}=21.92 \%$.

The technical and energy assessment of the application of a drying unit with infrared radiation and forced ventilation in comparison with the convective method of supplying heat during the preparation of feed materials for long-term storage showed that the drying time decreased by $28.9 \%$, the power spent on preparing the feed for long-term storage decreased by $52.4 \%$ and energy consumption per $1 \mathrm{~kg}$ of evaporated moisture decreased by $9.0 \%$ 


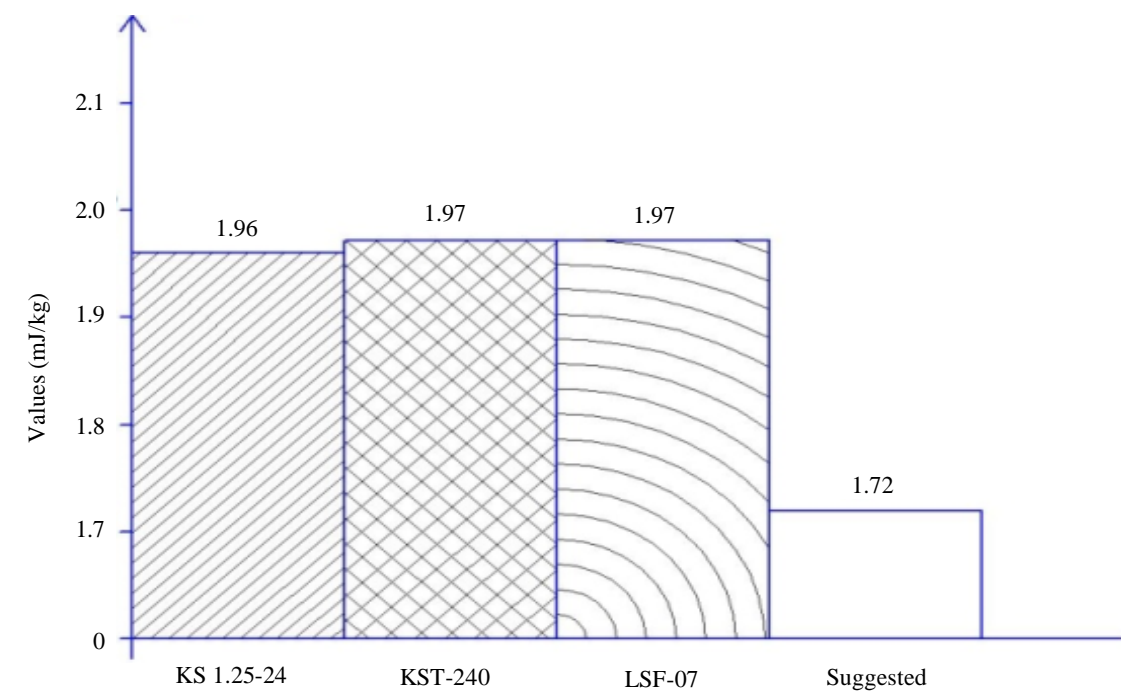

Fig. 8: Direct energy costs $(\mathrm{mJ} / \mathrm{kg})$

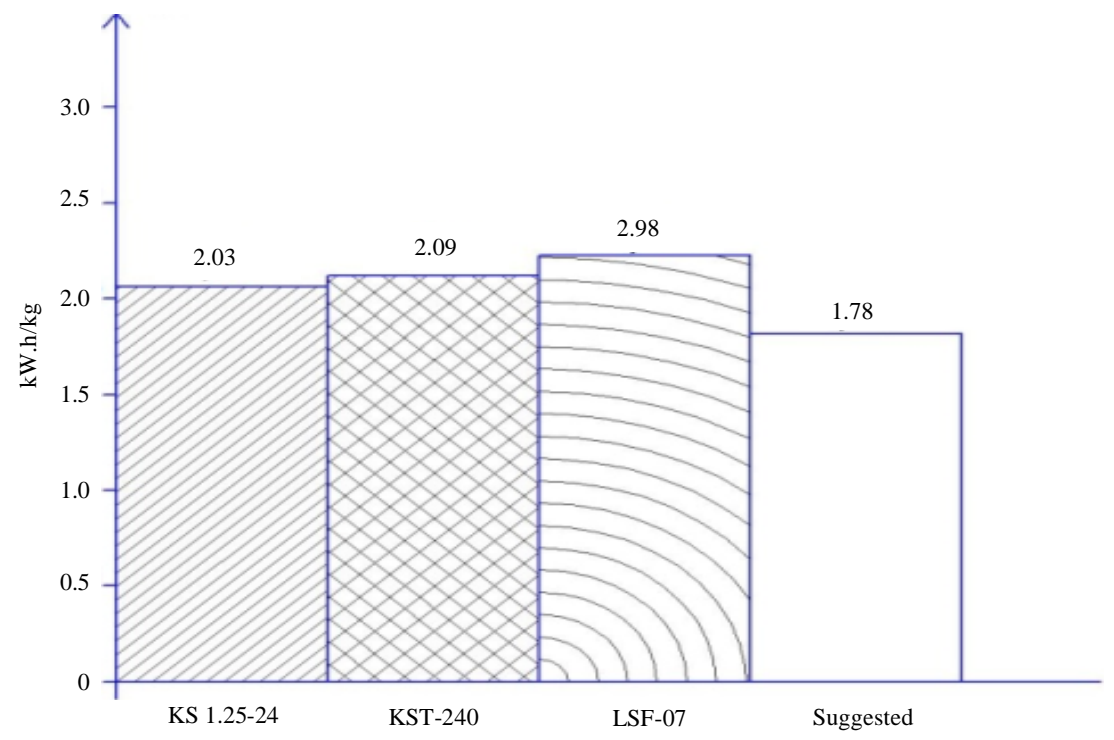

Fig. 9: Energy costs per $1 \mathrm{~kg}$ of evaporated moisture $(\mathrm{kWh} / \mathrm{kg})$

in comparison with the commonly used drying methods (Samarina et al., 2007; Zlatanovi et al., 2013).

The reliability of the obtained data is confirmed by the convergence of the theoretical justifications and experimental parameters determined in the real operating conditions of the infrared heating device. The comparison of these results with the data previously obtained by the researchers (Ginzburg, 1966; Jaturonglumlert and Kiatsiriroat, 2010; Kowalski and Mierzwa, 2013; Zlatanovi et al., 2013) proves the effectiveness of the proposed solution which has not been considered by the applied science in its entirety before now.
To confirm the results of the study, we compared several drying units, similar to the proposed one in main parameters (productivity and heating temperature of the product surface): convection unit KS 1.25-24, chamber dryer KST-240 and freeze dryer LSF-07.

The comparative assessment was carried out according to three main indicators: labor outlays, direct energy costs and energy costs per $1 \mathrm{~kg}$ of evaporated moisture (Fig. 7-9).

The analysis of the comparative assessment shows that the proposed infrared drying unit requires minimum costs for all the above energy indicators. 


\section{CONCLUSION}

The outlined studies allow us to conclude that the application of a combined drying unit with infrared radiation and forced ventilation in preparation of feed materials for long-term storage results in reduced drying time and minimization of energy costs per product unit. Consequently, the proposed drying unit with infrared radiation and forced ventilation is a highly efficient design intended for preparation of feed for long-term storage, that implements original ideas and has an engineering novelty.

\section{IMPLEMENTATIONS}

The results of the studies were implemented and are successfully used in feed production technology by several agricultural enterprises of the Amur Region including farms "Shilov L. F.", "Kovalevskiy V. A." and others.

\section{REFERENCES}

Borkhert, R. and V. Yubic, 1953. The Technology of Infrared Heating. Publisher Gosenergoizdat, Moscow, Russia, Pages: 375.

Cuccurullo, G., L. Giordano, D. Albanese, L. Cinquanta and D.M. Matteo, 2012. Infrared thermography assisted control for apples microwave drying. J. Food Eng., 112: 319-325.

Dongbang, W., W. Pirompugd and K. Triratanasirichai, 2010. The drying kinetics of chilies using a rotating fluidized bed technique. Am. J. Appl. Sci., 7: 1599-1606.

Eckert, E.R.G. and A.J. Diaguila, 1954. Convective heat transfer for mixed, free and forced flow through tubes. Trans. ASME, 76: 497-504.
Ginzburg, A.S., 1966. The infrared technology in the food industry. Food Industry, Moscow, Russian.

Jaturonglumlert, S. and T. Kiatsiriroat, 2010. Heat and mass transfer in combined convective and far-infrared drying of fruit leather. J. Food Eng., 100: 254-260.

Kowalski, S.J. and D. Mierzwa, 2013. Numerical analysis of drying kinetics for shrinkable products such as fruits and vegetables. J. Food Eng., 114: 522-529.

Lebedev, P.D., 1955. Drying under Infrared Rays. Publisher Gosenergoizdat, Moscow, Russia, Pages: 387.

Nair, P.A. and K. Karuppasamy, 2015. Comparitive study of Bayesian approach and least square residual optimization method in horizontal heated plate facing upward-an experimental approach. Intl. J. Res. Aeronaut. Mech. Eng., 3: 7-18.

Nair, P.A., K. Karuppasamy, B. Benziger and P. Balakrishnan, 2015. Natural convective heat transfer from horizontal heated plate facing upward in vertical channel-a review. Intl. J. Mech. Eng. Res., 5: 27-38.

Samarina, Y.R. and S.V. Shchitov, 2014. Estimation of energy costs for drying feed. Mach. Equip. Villages, 7: 27-28.

Samarina, Y.R., A.V. Yakimenko and V.P. Yakimenko, 2007. Wet pelletizing of feed mixes. Rural Mechanization Expert, 9: 36-37.

Samarina, Y.R., A.V. Yakimenko, T.Y. Samarina and I.V. Bumbar, 2012. Justification of parameters and drying regimes of an infrared drying unit. Mach. Equip. Villages, 12: 20-23.

Vanzetti, R., 1972. Practical Applications of the Infrared Technology: A New Tool in a new Dimension for Problem Solving. John Wiley \& Sons, Hoboken, New Jersey, USA., ISBN:9780471903604, Pages: 355.

Zlatanovic, I., M. Komatina and D. Antonijevic, 2013. Low-temperature convective drying of apple cubes. Appl. Thermal Eng., 53: 114-123. 